Tropical Journal of Pharmaceutical Research April 2017; 16 (4): 795-801

ISSN: $1596-5996$ (print); 1596-9827 (electronic)

(C) Pharmacotherapy Group, Faculty of Pharmacy, University of Benin, Benin City, 300001 Nigeria.

All rights reserved.

Available online at http://www.tjpr.org

Original Research Article

http://dx.doi.org/10.4314/tjpr.v16i4.8

\title{
Polysaccharides from Polygonatum odoratum strengthen antioxidant defense system and attenuate lipid peroxidation against exhaustive exercise-induced oxidative stress in mice
}

\author{
Hongjie Yang ${ }^{1 *}$ and Xianhao Zhang ${ }^{2}$ \\ ${ }^{1}$ Department of Physical Education, Yancheng Institute of Technology, Yancheng, Jiangsu 224051, ${ }^{2}$ Department of Physical \\ Education, Binzhou University, Binzhou, Shandong 256600, PR China
}

*For correspondence: Email: yonghongjie@sina.cn; Tel: 086-0515-88298285; Fax: 086-0515-88298285

Received: 9 November 2016

Revised accepted: 17 March 2017

\begin{abstract}
Purpose: To investigate the potential effects of polysaccharides isolated from Polygonatum odoratum (PPO) on oxidative stress induced by forced swimming exercise in mice.

Methods: Mice were randomly divided into four groups: one control group and three PPO groups. The mice in the control group were administered with only distilled water, whereas the mice in the PPO groups were treated with different doses $(150,300$, and $600 \mathrm{mg} / \mathrm{kg})$ of PPO, respectively. The treatments were performed by oral gavage once daily for 28 days, and were followed by forced swimming test to determine exhaustive swimming. Furthermore, various biochemical parameters, including lactate dehydrogenase ( $(D H)$, creatine kinase (CK), superoxide dismutase (SOD), glutathione peroxidase $(G P x)$, catalase $(C A T)$ and malondialdehyde $(M D A)$ were assessed.

Results: PPO significantly $(p<0.05)$ prolonged exhaustive swimming time. It also significantly $(p<$ $0.05)$ lowered $L D H$ and $C K$ levels in serum, as well as MDA levels in serum, liver and muscle, and also significantly $(p<0.05)$ improved SOD, GPx and CAT levels in serum, liver, and muscle.

Conclusion: PPO protects against oxidative stress induced by forced swimming exercise by strengthening antioxidant defense system and reducing lipid peroxidation. PPO may be suitable as a supplement for athletes and other physically active individuals for the improvement of exercise endurance and alleviation of fatigue.
\end{abstract}

Keywords: Polygonatum odoratum, Polysaccharides, Forced swimming test, Oxidative stress, Biochemical parameters

Tropical Journal of Pharmaceutical Research is indexed by Science Citation Index (SciSearch), Scopus, International Pharmaceutical Abstract, Chemical Abstracts, Embase, Index Copernicus, EBSCO, African Index Medicus, JournalSeek, Journal Citation Reports/Science Edition, Directory of Open Access Journals (DOAJ), African Journal Online, Bioline International, Open-J-Gate and Pharmacy Abstracts

\section{INTRODUCTION}

Reactive oxygen species (ROS) play a significant role in maintaining homeostasis through cellular signals and immune function [1]. It is well known that exercise increases the utilization of oxygen in the body, and therefore enhances the production of ROS [2]. Specific sources of ROS during exercise include myeloperoxidase, xanthine oxidase, NADH oxidase, peroxisomal oxidative enzymes, and the mitochondrial electron transport chain (ETC) [3]. Under normal physiological conditions, ROS are neutralized through a complicated endogenous antioxidant defense system that is comprised of enzymatic and non-enzymatic antioxidants [4]. Antioxidant enzymes include glutathione peroxidase, catalase, and superoxide dismutase. The 
principal non-enzymic antioxidants include reduced glutathione (GSH), vitamin $\mathrm{C}$, and vitamin $\mathrm{E}$ [5]. An imbalance can be produced by exhaustive exercise in ROS and antioxidant defense, which results in oxidative stress [6]. This harmful status may lead to oxidative damage in all cellular components, including proteins, nucleic acids, lipids, and carbohydrates [7]. Exhaustive exercise-induced oxidative stress may result in muscle fatigue, muscle damage, and a reduction in physical performance [8]. Several studies have indicated that dietary antioxidants may prevent exercise-induced oxidative damage, as they are able to detoxify a number of peroxides directly through scavenging ROS that are generated during exercise or indirectly as modulators of intracellular pro- and anti-oxidant enzymes [9].

Polygonatum odoratum (Mill.) Druce belongs to the Polygonatum (Liliaceae) genus, and is widely grown in China's Northeast, Central and Southwest fields [10]. Its rhizome, also referred to as "YuZhu", "WaiSheng", "WeiRui", or "LingDangCai" in Chinese, has been widely used as an ingredient or supplement in food supplies. Additionally, it is a well-known Chinese traditional medicine that functions in removing dryness, quenching thirst, promoting fluid secretion, and treatment of diverse diseases, including fatigue, hypo-immunity, diabetes, and cardiovascular disease $[11,12]$. Many studies have reported the biological activities of steroids, dipeptides, flavonoids, and polysaccharides isolated from $P$. odoratum [13]. Recent studies have demonstrated that polysaccharides are one of the principal bioactive components of $P$. odoratum, and the main monosaccharide compositions of polysaccharides are glucose, mannose, glucosamine, arabinose, rhamnose, and galactose [10]. Polysaccharides from $P$. odoratum (PPO) have been shown to possess antioxidant, antitumor, hypoglycemic, antifatigue, and immunomodulatory activities $[10,14,15]$. However, little is known about PPO's effects on oxidative stress induced by exhaustive exercise. Hence, the current study objective was to systematically investigate the potential effects of PPO on forced swimming exercise-induced oxidative stress in mice.

\section{EXPERIMENTAL}

\section{Plant material}

Dried rhizomes of $P$. odoratum were bought from a local herb store (Yancheng, China). The plant's authenticity was confirmed by Dr WY Shi, a plant taxonomist at School of Pharmaceutical Engineering, Yancheng Institute of Technology
(Yancheng, China). A voucher specimen (YTUPD-237) was kept in the herbarium of Yancheng Institute of Technology. The dried samples were crushed into a fine powder and then stored in an airtight container and maintained in a cool, dark, and dry place until further use.

\section{Chemicals and reagents}

The assay kit for lactate dehydrogenase (LDH) was bought from Beyotime Institute of Biotechnology (Shanghai, China), and that for creatine kinase (CK) was bought from Yuduo Biological Technology Co. (Shanghai, China). The assay kits for glutathione peroxidase (GPX), superoxide dismutase (SOD), catalase (CAT), and malondialdehyde (MDA) were bought from Jiancheng Biotechnology Co. (Nanjing, China). Unless otherwise noted, all other chemicals and reagents used were of analytical grade and used without further purification. All solutions used were made with double distilled water.

\section{Preparation of polysaccharides from $P$. odoratum}

Polysaccharides from $P$. odoratum were isolated as previously reported $[14,16]$ with small changes. Dried ground samples were extracted with distilled water at $90^{\circ} \mathrm{C}$ for approximately 2.5 $h$. The aqueous extract was filtered and centrifuged $\left(2,000 \times \mathrm{g}\right.$ for $10 \mathrm{~min}$, at $\left.20^{\circ} \mathrm{C}\right)$. The supernatant obtained was concentrated using a rotary evaporator at $60{ }^{\circ} \mathrm{C}$ under reduced pressure conditions, precipitated through adding ethanol to a final concentration of $80 \%(\mathrm{v} / \mathrm{v})$ and then incubated overnight. The resultant precipitate was dissolved in distilled water and deproteinized with the Sevag method, and again precipitated with ethanol to a final concentration of $80 \%(\mathrm{v} / \mathrm{v})$ and then incubated overnight. The precipitate was collected by centrifugation $(2,000$ $\times \mathrm{g}$ for $10 \mathrm{~min}$, at $20^{\circ} \mathrm{C}$ ), washed sequentially with ethanol, acetone, and ether, respectively, and then vacuum freeze-dried, resulting in crude polysaccharides.

\section{Experimental animals}

Male kunming mice, weighing $18 \pm 2 \mathrm{~g}$, were provided by the Laboratory Animal Breeding Center of Yancheng Institute of Technology and acclimatized to the test environment for one week before use. Mice were allowed to feed on the standard rodent pellet food and tap water ad libitum. The animals were housed in environmentally controlled conditions (humidity of $55 \pm 5 \%$, temperature of $22 \pm 1^{\circ} \mathrm{C}$ ) with a $12: 12$ hour light:dark cycle. Animal procedures were 
carried out in accordance with the National Institute of Health Guide for the Care and Use of Laboratory Animals [16], and approved by the Ethics Committee of Yancheng Institute of Technology (approval no. SYLL2015-0211).

\section{Experimental design}

After one week of adaptive feeding, the animals were divided into four groups at random $(n=8$ for each group): control (C) group, low-dose PPO treated (PT150) group, medium-dose PPO treated (PT300) group and high-dose PPO treated (PT600) group. The mice in the PPO treatment groups were administered increasing doses of PPO (150, 300 and $600 \mathrm{mg} / \mathrm{kg}$ body weight) by oral gavage once daily for 28 days, and mice in the control group were administered distilled water instead of PPO at the equivalent volume $(2.0 \mathrm{~mL})$. After final treatment with PPO or distilled water, a forced swimming test was performed as described in the literature $[17,18]$ with small changes. Briefly, the animals were permitted to rest for $30 \mathrm{~min}$ and were then loaded with a bundle of lead skin attached to their tails, which weighed $\sim 5 \%$ of their body weight. They were then placed in the swimming pool $(50 \times 50$ $\times 40 \mathrm{~cm}$ ) at a depth of $30 \mathrm{~cm}$ and kept at a temperature of $25 \pm 1^{\circ} \mathrm{C}$. The mice were determined as being exhausted by measuring the loss of coordinated movements and failure to come back to the surface of water within 10 seconds [17]. The exhaustive swimming times of the mice were used as a measure of exercise tolerance index.

\section{Biochemical analysis}

After the forced swimming test, the mice were sacrificed by decapitation under ether anesthesia, and the blood samples were collected in pre-sterilized tubes without the anticoagulant. Serum was obtained by the centrifugation $(3,000 \times \mathrm{g}$ for $10 \mathrm{~min})$ at room temperature, and stored at $-20{ }^{\circ} \mathrm{C}$ until use. Following blood collection, tissue samples from hind-limb skeletal muscle and liver were excised rapidly and rinsed in ice-cold physiological saline, rapidly frozen in liquid nitrogen, and kept at -80 ${ }^{\circ} \mathrm{C}$ for further analysis.

All biochemical parameters, including LDH, CK, SOD, GPx, CAT, and MDA were determined using their respective manufacturers' analytical kits. Levels of LDH were measured using the enzymatic colorimetry method based on the fact that $\mathrm{LDH}$ can catalyze the reduction of pyruvate into lactic acid, while NADH oxidizes to $\mathrm{NAD}^{+}$. Absorbance detection was set at $340 \mathrm{~nm}$ [19].
CK levels were determined using the molybdenum acid ammonium method based on the fact that CK catalyzes ATP and creatine to produce creatine phosphate (CP), which is quickly hydrolyzed to phosphoric acid. The addition of molybdenum acid ammonium produces phosphomolybdic acid, which can be further reduced to molybdenum blue. Enzymatic activity was calculated from the amount of inorganic phosphorus produced, and absorbance detection was set at $660 \mathrm{~nm}$ [20]. SOD levels were determined by the xanthine oxidase method, as the xanthine and xanthine oxidase reaction systems produce superoxide anion, which oxidize hydroxylamine to form nitrite. The ability of SOD to inhibit nitrite formation by superoxide anion was used as an indicator of enzyme activity. The absorbance detection was set at $550 \mathrm{~nm}$ [21]. GPx was measured by DTNB (5,5'-dithiobis-2-nitrobenzoic acid) method, as GPx can catalyze the reaction of $\mathrm{H}_{2} \mathrm{O}_{2}$ and reduced glutathione (GSH) to produce $\mathrm{H}_{2} \mathrm{O}$ and oxidized glutathione (GSSG). Enzyme activity was calculated by measuring the GSH consumption in the enzymatic reaction. GSH reacts with DTNB to produce TNB (5-thio-2nitrobenzoic acid) and GSSG, and with an absorbance detection at $412 \mathrm{~nm}$, it can be calculated the amount of GSH [22]. CAT levels were determined by the ammonium molybdate method, as CAT decomposition of $\mathrm{H}_{2} \mathrm{O}_{2}$ can be interrupted by adding ammonium molybdate. The reaction of the remaining $\mathrm{H}_{2} \mathrm{O}_{2}$ with ammonium molybdate produced a yellow complex, and an absorbance detection set at $405 \mathrm{~nm}$ was used to calculate enzyme activity [23]. MDA contents were determined by the thiobarbituric acid method, as the reaction of the MDA with TBA produces a red MDA-TBA adduct, which has a maximum absorption peak of $535 \mathrm{~nm}$ [24]. The tissue protein contents were determined by the coomassie bright-blue stain method.

\section{Statistical analysis}

The data are presented as mean \pm SD. Statistical analysis was carried out by one-way analysis of variance (ANOVA) using SPSS 18.0 software (SPSS Inc., Chicago, USA) and Dunnett's test. Significant differences was set at $p<0.05$.

\section{RESULTS}

\section{Effect of PPO on exhaustive swimming time}

The exhaustive swimming time of the PT150, PT300, and PT600 groups were significantly longer than those of $\mathrm{C}$ group $(p<0.05$, Figure 1$)$. 


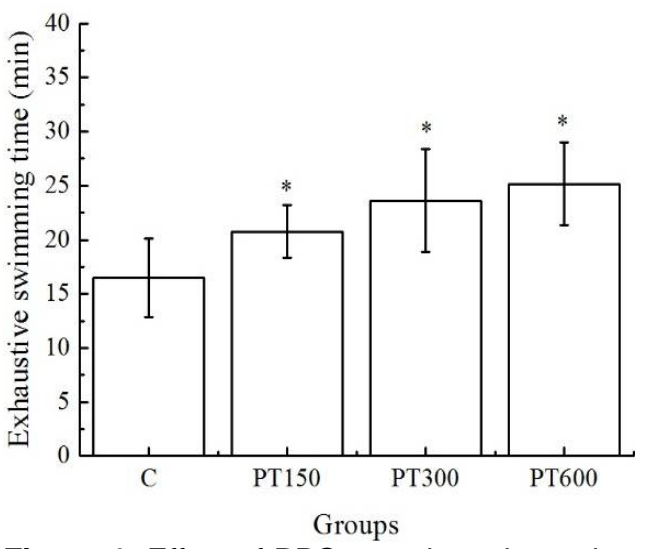

Figure 1: Effect of PPO on exhaustive swimming time of mice. Data are presented as mean $\pm \mathrm{SD}(\mathrm{n}=8) ;{ }^{*} p$ $<0.05$ as compared with group $\mathrm{C}$

\section{Effect of PPO on serum LDH and CK levels of mice}

The LDH levels in the serum of the PT150, PT300, and PT600 groups, as well as the CK levels in serum of the PT300 and PT600 groups, were significantly lower than those of group $\mathrm{C}(p$ $<0.05$ ) (Fig. 2).

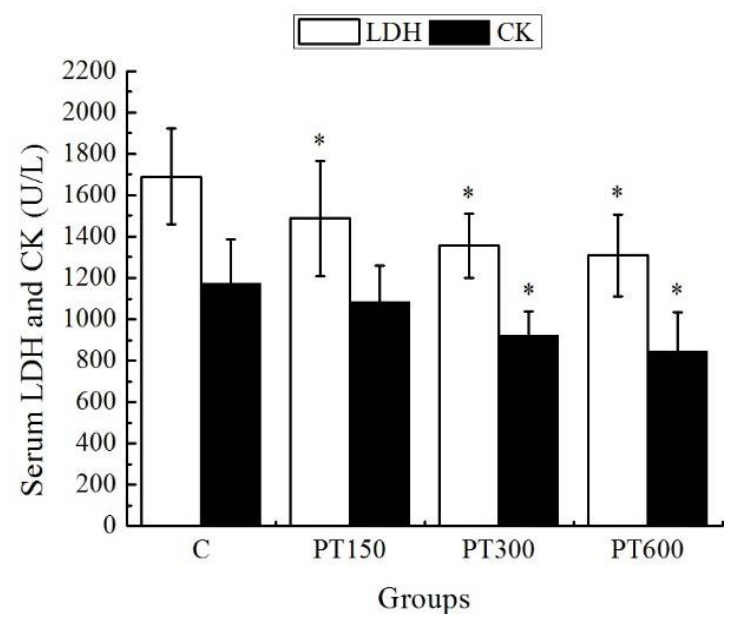

Figure 2: Effect of PPO on serum LDH and CK levels of mice. Data are presented as mean $\pm \mathrm{SD}(\mathrm{n}=8) ;{ }^{*} p$ $<0.05$ compared with group $\mathrm{C}$

\section{Effect of PPO on SOD, GPx and CAT levels in serum, liver, and muscle of mice}

As can be seen from Figure 3a, SOD levels in the serum and liver of the PT150, PT300, and PT600 groups, as well as the SOD levels in muscle from the PT300 and PT600 groups, were significantly higher than those of the C group $(p<$ $0.05)$. GPx levels in serum, liver, and muscle of the PT150, PT300, and PT600 groups were significantly higher than those of the $\mathrm{C}$ group $(p<$ 0.05 ) (Figure $3 b$ ). The CAT levels in serum and muscle of the PT300 and PT600 groups, as well as the CAT levels in liver of the PT150, PT300, and PT600 groups, were significantly higher than those of group $\mathrm{C}(p<0.05)$ (Figure $3 \mathrm{c})$.
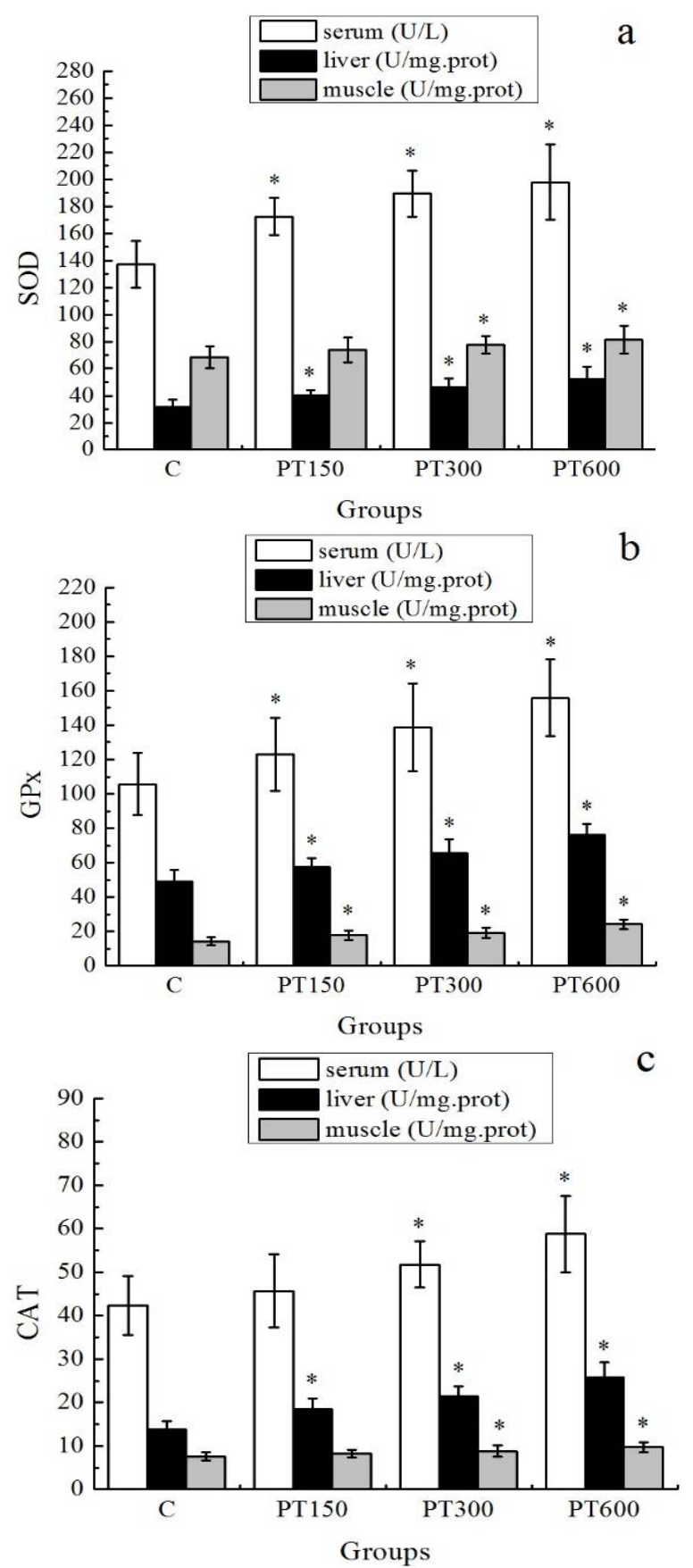

Figure 3: Effect of PPO on SOD, GPx and CAT levels in serum, liver, and muscle of mice. Data are presented as mean $\pm \mathrm{SD}(\mathrm{n}=8) ;{ }^{*} p<0.05$ compared to group C

\section{Effect of PPO on MDA content in serum, liver, and muscle of mice}

In comparison with group $\mathrm{C}$, the MDA content in the serum of the PT150, PT300, and PT600 groups, as well as the MDA content in the liver and muscle of the PT300 and PT600 groups, were significantly lower $(p<0.05)$ (Figure 4$)$. 


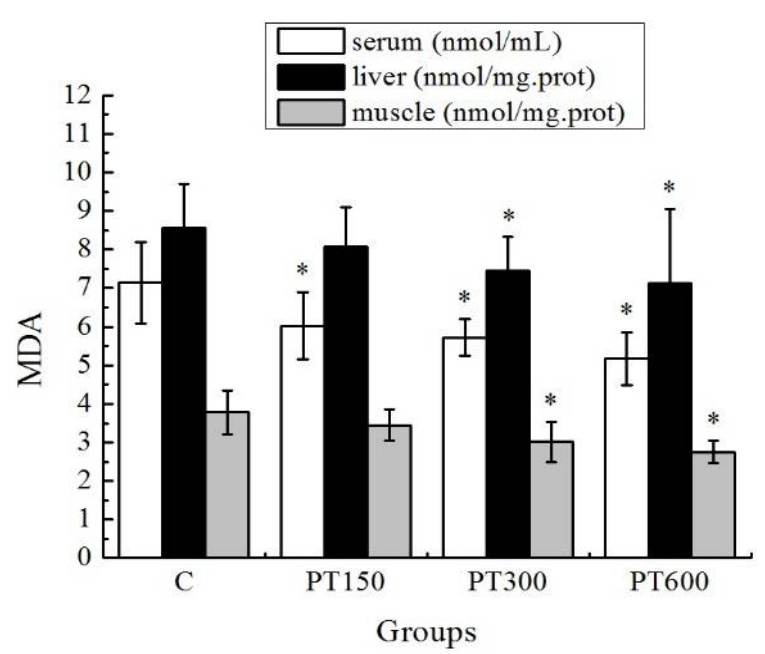

Figure 4: Effect of PPO on MDA content in serum, liver, and muscle of mice. Data are presented as mean $\pm \mathrm{SD}(\mathrm{n}=8) ;{ }^{*} p<0.05$ compared with $\mathrm{C}$ group $\mathrm{C}$

\section{DISCUSSION}

Forced swimming tests have been widely used to evaluate the anti-fatigue properties of natural products $[25,26]$. This method results in less mechanical stress and damage, and a better redistribution of blood flow in the tissues without significant changes in cardiac output and heart rate, which can in turn lead to an amount of damage that is caused by production of ROS [27]. In the present study, the significant increase in the exhaustive swimming time of various dose PPO treatment groups indicated that PPO has anti-fatigue properties.

It has been shown that exhaustive exercise causes a rise in oxygen consumption in tissues, leading to an increase in ROS production. Failure to get rid of ROS may result in a certain degree of muscle damage [28]. Serum LDH and CK are widely recognized as indicators of muscle damage after exhaustive exercise. As cytosolic enzymes, LDH and CK are physiologically abundant in organs' cells (e.g., heart, kidney, and skeletal muscles). However, during the process of exhaustive exercise, excessive ROS causes muscle cell damage, which increases LDH and CK in the blood [6]. The data from the present study showed that PPO significantly decreased serum LDH and CK levels of mice, implying that PPO had a preventive effect on exercise-induced muscle damage. This may be one of the reasons that PPO can extend the exhaustive swimming time of mice.

Numerous studies have demonstrated that antioxidant enzymes play an important function in preventing exercise-induced oxidative stress, and reduced activities or expressions of antioxidant enzymes may cause free radical damage in tissues [29]. As the first line of defense in the body against oxidative stress, SOD can completely inactivate superoxide anion radicals [30]. The two other key antioxidant enzymes in living body are GPx and CAT. GPx can convert GSH to GSSG, reducing toxic peroxide to non-toxic hydroxyl compounds, while promoting the decomposition of $\mathrm{H}_{2} \mathrm{O}_{2}$. GPx is regarded as an efficient protective enzyme on lipid peroxidation. CAT is mainly concentrated in the peroxisomes, which are responsible for the elimination of $\mathrm{H}_{2} \mathrm{O}_{2}$ produced from long-chain fatty acids metabolism [31]. In the present study, the significant increase in SOD, GPx, and CAT levels in serum, liver, and muscle of various dose PPO treatment groups indicated that PPO could strengthen the antioxidant defense system by upregulating the main antioxidant enzyme activities in response to the oxidative stress that is induced by the exhaustive exercise.

Excessive accumulation of ROS after exhaustive exercise can lead to lipid peroxidation of polyunsaturated fatty acids in biofilm and blood, and interfere with cell function [32]. Lipid peroxidation can cause fluidity loss and permeability increase of membranes, leading to the loss of cytosolic proteins [33]. Inhibition of lipid peroxidation is essential for maintaining normal cell function [34]. MDA is one of the end products of the unsaturated fatty acid peroxidation in phospholipids, and has been widely used as a marker of oxidative stress [4]. In the present study, PPO significantly decreased the MDA levels in serum, liver, and muscle of various dose PPO treatment groups, indicating that PPO can effectively attenuate lipid peroxidation.

\section{CONCLUSION}

The findings of the present study demonstrate that PPO has protective effects on exhaustive exercise-induced oxidative stress by strengthening the antioxidant defense system and reducing lipid peroxidation. Therefore, PPO has the potential to be developed as a supplement for athletes and other physically active individuals for improvement of exercise endurance and alleviation of fatigue.

\section{DECLARATIONS}

\section{Acknowledgement}

This study was supported by Binzhou University Foundation Science Research Fund (Grant no. BZUF2014065). 


\section{Conflict of Interest}

No conflict of interest associated with this work.

\section{Contribution of Authors}

The authors declare that this work was done by the authors named in this article and all liabilities pertaining to claims relating to the content of this article will be borne by them.

\section{Open Access}

This is an Open Access article that uses a funding model which does not charge readers or their institutions for access and distributed under the terms of the Creative Commons Attribution License (http://creativecommons.org/licenses/by/ 4.0) and the Budapest Open Access Initiative (http://www.budapestopenaccessinitiative.org/rea d), which permit unrestricted use, distribution, and reproduction in any medium, provided the original work is properly credited.

\section{REFERENCES}

1. Takahashi M, Suzuki K, Kim HK, Otsuka Y, Imaizumi A, Miyashita M, Sakamoto S. Effects of curcumin supplementation on exercise-induced oxidative stress in humans. Int J Sports Med 2014; 35: 469-475.

2. Petibois $C$, Déléris G. Analysis and monitoring of oxidative stress in exercise and training by FTIR spectrometry. Int J Sports Physiol Perform 2008; 3: 119130.

3. Aguiló A, Tauler P, Fuentespina E, Tur JA, Córdova A, Pons A. Antioxidant response to oxidative stress induced by exhaustive exercise. Physiol Behav 2005; 84: 1-7.

4. Yan F, Wang B, Zhang $Y$. Polysaccharides from Cordyceps sinensis mycelium ameliorate exhaustive swimming exercise-induced oxidative stress. Pharm Biol 2014; 52: 157-161.

5. Cooper CE, Vollaard NB, Choueiri T, Wilson MT. Exercise, free radicals and oxidative stress. Biochem Soc Trans 2002; 30: 280-285.

6. Zhao XN, Liang JL, Chen HB, Liang YE, Guo HZ, Su ZR, Li YC, Zeng HF, Zhang XJ. Anti-fatigue and antioxidant activity of the polysaccharides isolated from Millettiae speciosae Champ. Leguminosae. Nutrients 2015; 7: 8657-8669.

7. Pingitore A, Lima GP, Mastorci F, Quinones A, lervasi G, Vassalle $C$. Exercise and oxidative stress: potential effects of antioxidant dietary strategies in sports. Nutrition 2015; 31: 916-922.

8. Jówko E, Sacharuk J, Balasińska B, Ostaszewski P, Charmas $M$, Charmas $R$. Green tea extract supplementation gives protection against exercise- induced oxidative damage in healthy men. Nutr Res 2011; 31: 813-821.

9. Voces J, Cabral de Oliveira AC, Prieto JG, Vila L, Perez AC, Duarte ID, Alvarez Al. Ginseng administration protects skeletal muscle from oxidative stress induced by acute exercise in rats. Braz J Med Biol Res 2004; 37: 1863-1871.

10. Liu X, Zhang M, Guo K, Jia A, Shi Y, Gao G, Sun Z, Liu C. Cellulase-assisted extraction, characterization, and bioactivity of polysaccharides from Polygonatum odoratum. Int J Biol Macromol 2015; 75: 258-265.

11. Zhao XH, Zeng J, Gao HY, Wang Y. Optimization and composition of volatile Oil from Polygonatum odoratum (Mill Druce) using supercritical fluid extraction. Trop $J$ Pharm Res 2014; 13: 779-786.

12. Zhang $H$, Chen L, Kou JP, Zhu DN, Qi J, Yu BY. Steroidal sapogenins and glycosides from the fibrous roots of Polygonatum odoratum with inhibitory effect on tissue factor (TF) procoagulant activity. Steroids 2014; 89: 1-10.

13. Wang $D$, Zeng L, Li D, Pu W. Antioxidant activities of different extracts and homoisoflavanones isolated from the Polygonatum odoratum. Nat Prod Res 2013; 27: 1111-1114.

14. GH Lan, HX Chen, ZS Wang, WJ Zhang, LK Zhang. Extraction of Polygonatum odoratum polysaccharides using response surface methodology and preparation of a compound beverage. Carbohyd Polym 2011; 86: 1175-1180.

15. Chen $Y$, Yin L, Zhang $X$, Wang $Y$, Chen $Q$, Jin $C, H u Y$, Wang J. Optimization of alkaline extraction and bioactivities of polysaccharides from rhizome of Polygonatum odoratum. Biomed Res Int 2014; 2014: 504896.

16. Liang $D$, Zhou Q, Gong W, Wang Y, Nie Z, He H, Li J, $W u J$, Wu C, Zhang J. Studies on the antioxidant and hepatoprotective activities of polysaccharides from Talinum triangulare. J Ethnopharmacol 2011; 22: 316321.

17. Yong-xin X, Jian-jun Z. Evaluation of anti-fatigue activity of total saponins of Radix notoginseng. Indian $J$ Med Res 2013; 137: 151-155.

18. Wang X, Xing R, Chen Z, Yu H, Li R, Li P. Effect and mechanism of mackerel (Pneumatophorus japonicus) peptides for anti-fatigue. Food Funct 2014; 5: $2113-$ 2119.

19. Lao F, Li W, Han D, Qu Y, Liu Y, Zhao Y, Chen C. Fullerene derivatives protect endothelial cells against NO-induced damage. Nanotechnology 2009; 20: 225103.

20. Yan J, Qian Z, Sheng L, Zhao B, Yang L, Ji H, Han X, Zhang R. $F$ Effect of crocetin on blood pressure restoration and synthesis of inflammatory mediators in heart after hemorrhagic shock in anesthetized rats. Shock 2010; 33: 83-87.

21. Li Y, Bao Y, Jiang B, Wang Z, Liu Y, Zhang C, An L. Catalpol protects primary cultured astrocytes from in 
vitro ischemia-induced damage. Int $J$ Dev Neurosci 2008; 26: 309-317.

22. Thilagam H, Gopalakrishnan S, Qu HD, Bo J, Wang KJ. $17 \beta$ estradiol induced ROS generation, DNA damage and enzymatic responses in the hepatic tissue of Japanese sea bass. Ecotoxicology 2010; 19: 12581267.

23. Yu M, Li SM, Li XY, Zhang BJ, Wang JJ. Acute effects of 1-octyl-3-methylimidazolium bromide ionic liquid on the antioxidant enzyme system of mouse liver. Ecotoxicol Environ Saf. 2008; 71: 903-908.

24. Yuan GJ, Ma JC, Gong ZJ, Sun XM, Zheng SH, Li X. Modulation of liver oxidant-antioxidant system by ischemic preconditioning during ischemia/reperfusion injury in rats. World J Gastroenterol. 2005;28: 18251828.

25. Can A, Dao DT, Arad M, Terrillion CE, Piantadosi SC, Gould TD. The mouse forced swim test. J Vis Exp 2012; 59: 3638.

26. Liang D, Zhou Q, Gong W, Wang Y, Nie Z, He H, Li J, Wu J, Wu C, Zhang J. Studies on the antioxidant and hepatoprotective activities of polysaccharides from Talinum triangulare. J Ethnopharmacol 2011; 22: 316321.

27. Aydin C, Ince E, Koparan S, Cangul IT, Naziroglu M, Ak $F$. Protective effects of long term dietary restriction on swimming exercise-induced oxidative stress in the liver, heart and kidney of rat. Cell Biochem Funct 2007; 25 . 129-037.
28. Lu HK, Hsieh CC, Hsu JJ, Yang YK, Chou HN. Preventive effects of Spirulina platensis on skeletal muscle damage under exercise-induced oxidative stress. Eur J Appl Physiol 2006; 98: 220-226.

29. Lee SP, Mar GY, Ng LT. Effects of tocotrienol-rich fraction on exercise endurance capacity and oxidative stress in forced swimming rats. Eur J Appl Physiol 2009; 107: 587-595.

30. Pham-Huy LA, He H, Pham-Huy C. Free radicals, antioxidants in disease and health. Int $\mathrm{J}$ Biomed Sci 2008; 4: 89-96.

31. Zheng X, Long W, Liu G, Zhang X, Yang X. Effect of seabuckthorn (Hippophae rhamnoides ssp. sinensis) leaf extract on the swimming endurance and exhaustive exercise-induced oxidative stress of rats. J Sci Food Agric 2012; 92: 736-742.

32. Hsieh CC, Lee MY, Chen CC, Hsu JJ, Lu HK, Wang C. Hibiscus protocatechuic acid supplementation reduces oxidative stress induced by exhaustive exercise in rat muscle. J Exerc Sci Fit 2006; 4: 59-64.

33. Niu AJ, Wu JM, Yu DH, Wang R. Protective effect of Lycium barbarum polysaccharides on oxidative damage in skeletal muscle of exhaustive exercise rats. Int $\mathrm{J}$ Biol Macromol 2008; 42: 44744-4479.

34. Yu SH, Huang HY, Korivi M, Hsu MF, Huang CY, Hou CW, Chen CY, Kao CL, Lee RP, Lee SD, Kuo CH. Oral Rg1 supplementation strengthens antioxidant defense system against exercise-induced oxidative stress in rat skeletal muscles. J Int Soc Sports Nutr 2012; 9: 2-6. 